\begin{tabular}{|c|l|}
\hline Title & Two-step plasma electrolytic oxidation of Ti-15V-3A I-3Cr-3Sn for wear-resistant and adhesive coating \\
\hline Author(s) & Tsunekawa, S.; A oki, Y.; Habazaki, H. \\
\hline Citation & $\begin{array}{l}\text { Surface and Coatings Technology, 205(19), 4732-4740 } \\
\text { https://doi.org/10.1016/.surfcoat.2011.04.060 }\end{array}$ \\
\hline Issue Date & 2011-06-25 \\
\hline Doc URL & http://hdl.handle.net/2115/46827 \\
\hline Type & article (author version) \\
\hline File Information & SCT 205-19_4732-4740.pdf \\
\hline
\end{tabular}

Instructions for use 


\title{
Two-step plasma electrolytic oxidation of Ti-15V-3Al-3Cr-3Sn for wear-resistant and adhesive coating
}

\author{
S. Tsunekawa, Y. Aoki and H. Habazaki* \\ Division of Materials Chemistry, Faculty of Engineering, Hokkaido University, Sapporo \\ 060-8628, Japan
*Corresponding author: Phone \& Fax: +81-11-706-6575, e-mail: habazaki@eng.hokudai.ac.jp

Ti-15V-3Al-3Cr-3Sn (Ti-15-3) is one of the important practical titanium alloys with high cold deformability and high mechanical strength, but its wear resistance is poor. This paper reports the formation of wear-resistant and adhesive ceramic coatings on Ti-15-3 by two-step plasma electrolytic oxidation (PEO). The PEO of Ti-15-3 has been carried out first in alkaline aluminate electrolyte to form a wear-resistant oxide layer and then in acid electrolyte containing both phosphoric acid and sulphuric acid to improve adhesion of the coating. The coating formed in the alkaline aluminate electrolyte is more than $10 \mu \mathrm{m}$ thick, and highly crystalline. The main phase is $\mathrm{Al}_{2} \mathrm{TiO}_{5}$. This coating shows high wear resistance, but is not adherent to substrate due to the development of a number of voids and pores in the oxide layer close to the substrate. A new oxide layer with amorphous structure is formed next to the substrate in the subsequent PEO in the acid electrolyte, during which the voids are filled with a new 
oxide formed in the acid electrolyte, reducing the porosity. As a consequence, the adhesion of the coating is markedly improved without deteriorating the high wear resistance.

Keywords: plasma electrolytic oxidation, wear resistance, titanium alloy, coating adhesion

\section{Introduction}

Plasma electrolytic oxidation (PEO), also often referred as to micro-arc oxidation and spark anodizing, is a method of ceramic coatings, typically 10 to $100 \mu \mathrm{m}$ in thickness, on light metals of aluminium, magnesium, titanium and their alloys in aqueous electrolytes at ambient temperature [1, 2]. Highly crystalline oxide coatings are generally produced by PEO due to an exposure of coatings at high temperatures of more than $1000^{\circ} \mathrm{C}$ at local and instantaneous microdischarge sites during PEO [3-6]. Even though the coatings are exposed to high temperatures, the metallic substrates are usually kept at relatively low temperatures; no degradation of mechanical properties of metallic substrates occurs during PEO. Thus, the PEO coatings are promising for corrosion protection of aluminium and magnesium [7-18], wear resistance of light metals and their alloys [9, 19-30], and improved biofunctionality of titanium [31-33].

Ti-15V-3Al-3Cr-3Sn (Ti-15-3) is one of the practically used $\beta$-titanium alloys, with superior cold deformability in the $\beta$ solution treated condition and a high mechanical strength after $\alpha$ phase precipitation aging. However, a main limit of this alloy is poor tribological behaviour, characterized by high friction coefficients and 
severe adhesive wear. PEO is one of the promising techniques to improve the tribological behaviour of Ti-15-3 by a ceramic coating. Recently, some of the present authors reported the PEO of Ti-15-3 in alkaline aluminate electrolyte, by which wear resistance was highly improved [20]. A highly crystalline oxide coating, consisting mainly of $\mathrm{Al}_{2} \mathrm{TiO}_{5}$, was developed and the wear rate was reduced by many orders of magnitude after the coating. However, the coating was not highly adherent to the substrate [34]. In the present work, two-step PEO of Ti-15-3, first in alkaline aluminate electrolyte and subsequently in acid electrolyte, has been carried out to improve adhesion of the wear-resistant coating. The PEO coatings developed in the present study have been characterized using X-ray diffraction, SEM and STEM with a particular attention paying to the structure of the coating/substrate interface for elucidating the adhesion of the coatings.

\section{Experimental}

Plate specimens (15 x 15 x $1 \mathrm{~mm}$ ) of Ti-15-3 (14.91 wt\% vanadium, $3.01 \mathrm{wt} \%$ aluminium, $3.15 \mathrm{wt} \%$ chromium, $2.88 \mathrm{wt} \%$ tin, $0.22 \mathrm{wt} \%$ iron and $0.10 \mathrm{wt} \%$ oxygen) were used in this work. The surface of specimen was degreased ultrasonically in acetone prior to anodizing. Then, a commercially pure titanium lead wire was welded to the specimen, and an entire surface of the specimen was immersed in electrolyte for PEO treatment. Plasma electrolytic oxidation was carried out using a two-electrode cell in a water-cooled type 304 stainless steel bath when alkaline electrolyte was used. The stainless steel container also served as a counter electrode. For the PEO in acid electrolyte, a platinum plate was used as a counter electrolyte and PEO was conducted in a glass beaker. Alkaline electrolyte containing $0.15 \mathrm{~mol} \mathrm{dm}^{-3} \mathrm{~K}_{2} \mathrm{Al}_{2} \mathrm{O}_{4}, 0.02 \mathrm{~mol} \mathrm{dm}^{-3}$ 
$\mathrm{Na}_{3} \mathrm{PO}_{4}$ and $0.015 \mathrm{~mol} \mathrm{dm}^{-3} \mathrm{NaOH}$ and acid electrolyte with $0.1 \mathrm{~mol} \mathrm{dm}^{-3} \mathrm{H}_{2} \mathrm{SO}_{4}$ and $0.1 \mathrm{~mol} \mathrm{dm}{ }^{-3} \mathrm{H}_{3} \mathrm{PO}_{4}$ were prepared from reagent-grade chemicals and milli-Q water. The acid electrolyte containing both sulphuric acid and phosphoric acid was used since the coating growth proceeded more rapidly in the mixed electrolyte in comparison with the electrolyte containing only phosphoric acid. The PEO treatment was carried out using a square waveform with $2.0 \mathrm{kA} \mathrm{m}^{-2}$ and $-1.0 \mathrm{kA} \mathrm{m}^{-2}$ at $100 \mathrm{~Hz}$. A Takasago, AA2000XG2 power supply was used to generate the waveform. In alkaline electrolyte, the PEO treatment was continued until the anodic peak voltage reached $380 \mathrm{~V}$. In the acid electrolyte, the PEO treatment was carried out to the anodic peak voltage of $380 \mathrm{~V}$, but in the case of the second treatment after alkaline PEO, acid PEO was carried out for 100 s. During PEO treatments, the intensity of light emission from the specimen surface due to micro-discharges was measured using an Advantest TQ8215 optical power meter with a TQ82014 silicon photo-diode sensor (detectable wavelength: 400-1100 nm).

The thicknesses of the PEO coatings formed were measured by an eddy current thickness meter (Kett, LH-300C). The phases in the coatings were identified by X-ray diffraction (XRD) of $\theta-2 \theta$ mode using $\mathrm{Cu} K \alpha$ radiation $(\lambda=0.151418 \mathrm{~nm})$. XRD patterns were obtained using a Rigaku RINT2000 system. Surface and cross-sections of the specimens were observed by a JEOL JSM-6390LV scanning electron microscope (SEM) equipped with energy dispersive X-ray spectroscopy (EDS) facilities.

The coated specimens were further examined by a Hitachi, HD-2000 scanning transmission electron microscope (STEM). Electron-transparent sections were prepared using a Hitachi, FB-2100 focused ion beam system.

Adhesion of the coatings to alloy substrate was evaluated using a DeFelsko pull-off adhesion tester. Wear-resistance of the coatings was studied by means of dry 
sliding tests with a ball-on-disk tribometer (CSM Instruments). The tests were carried out under unlubricated condition at ambient atmosphere, with a sliding speed of $1.00 \mathrm{~cm}$ $\mathrm{s}^{-1}$, for a sliding distance of $25 \mathrm{~m}$, under a load of $2 \mathrm{~N}$ of SUJ2 steel ball of $6 \mathrm{~mm}$ diameter. After the tests, the wear depths of the coatings were evaluated by surface profilometer (Tokyo Seimitsu Co., SURFCOM 130A). As-coated specimens were used for the wear test, since all the coated specimens had similar surface roughness.

\section{Results and Discussion}

\subsection{Coating behaviour}

Fig. 1 shows the changes in the anodic peak voltage with time of PEO treatments in alkaline and acid electrolytes. The intensities of light emission during the PEO treatments are also shown in this figure. In the alkaline aluminate electrolyte, the peak voltage increases rapidly to $200 \mathrm{~V}$ within $30 \mathrm{~s}$, and then a plateau voltage of 220-230 V appears before the peak voltage increases again gradually to $380 \mathrm{~V}$. The appearance of the plateau voltage is typical of $\mathrm{Ti}-15-3$, and for commercially pure titanium and Ti-6Al-4V, the peak voltage increased continuously to $380 \mathrm{~V}$ under the present condition [34]. In the $\mathrm{H}_{2} \mathrm{SO}_{4}+\mathrm{H}_{3} \mathrm{PO}_{4}$ acid electrolyte, the peak voltage increases more rapidly to $220 \mathrm{~V}$. Then, the rate of voltage rise is reduced, but the voltage increases continuously to $380 \mathrm{~V}$ with the rate of voltage rise being further reduced over $\sim 300 \mathrm{~V}$. When the specimen is PEO-treated in the acid electrolyte after the PEO treatment in the alkaline electrolyte to $380 \mathrm{~V}$, the initial voltage surge is only $160 \mathrm{~V}$ and during PEO treatment, the voltage gradually decreases to $\sim 100 \mathrm{~V}$. Thus, the voltage-time responses in the acid electrolyte are markedly different for the specimens with and without a PEO 
coating formed in alkaline electrolyte. Such different behaviour is the subject of future study.

The intensity of light emission during PEO in the alkaline aluminate electrolyte is higher than that in the acid electrolyte. As expected, the light emission in the acid electrolyte after the PEO in the alkaline electrolyte is much lower than that without prior PEO in the alkaline electrolyte (Fig. 1b), since the peak voltage is considerably lower in the former case. The light emission due to micro-discharges commences at shorter time in the acid electrolyte because of more rapid initial voltage rise. In the alkaline electrolyte, the intensity of light emission is almost constant in the voltage plateau region, followed by gradual increase of the intensity of light emission during subsequent voltage rise. The lower intensity of light emission in the acid electrolyte in comparison with the alkaline electrolyte indicates that the light emission intensity is not directly correlated with the peak voltage, since the peak voltage is lower in the alkaline electrolyte than in the acid electrolyte.

\subsection{Characterization of coatings}

Thicknesses of the coatings formed in acid and alkaline PEO as well as two-step PEO are shown in Table 1. Relatively thin coating is developed in the acid electrolyte, compared with that in the alkaline electrolyte. It has been reported that the rapid coating growth occurs at sites of dielectric breakdown $[35,36]$. Thus, the relatively thin coating in the acid electrolyte is associated with the relatively weak micro-discharges during PEO processing. The fact that the coating thickness is not obviously increased after the second step PEO in the acid electrolyte should be also associated with negligibly low light emission in the second step PEO. 
The crystallinity of the coatings during PEO is also correlated to the intensity of light emission. Highly crystalline oxides are present in the coatings formed in the alkaline PEO and in the two-step PEO (Fig. 2). The main oxide in the coatings is $\mathrm{Al}_{2} \mathrm{TiO}_{5}$; rutile and $\gamma-\mathrm{Al}_{2} \mathrm{O}_{3}$ are also present as minor oxides. The formation of these phases is in agreement with the previous studies [20, 34, 37]. Although a small amount of aluminium is contained in Ti-15-3, the aluminium to form $\mathrm{Al}_{2} \mathrm{TiO}_{5}$ and $\gamma-\mathrm{Al}_{2} \mathrm{O}_{3}$ must be derived mainly from the alkaline aluminate electrolyte, since the coatings of similar composition were produced on aluminium-free, commercially pure titanium [34]. $\alpha-\mathrm{Al}_{2} \mathrm{O}_{3}$ has been often found in the coatings formed on titanium alloys in alkaline aluminate electrolytes [38, 39]. Its formation is influenced by the cathodic pulse in bipolar pulse PEO [38]. Low cathodic current, with respect to the anodic current, enhances the formation of $\alpha-\mathrm{Al}_{2} \mathrm{O}_{3}$, probably due to an increase in the instantaneous temperature of the coating by micro-discharges to higher than $1000^{\circ} \mathrm{C}$. The formation of $\alpha-\mathrm{Al}_{2} \mathrm{O}_{3}$ may be preferable in terms of tribology, since $\alpha-\mathrm{Al}_{2} \mathrm{O}_{3}$ is harder than $\gamma-\mathrm{Al}_{2} \mathrm{O}_{3}$. Although highly crystalline oxide phases are formed in the alkaline electrolyte, the underlying alloy substrate is still in the $\beta$ phase; no transformation from the metastable $\beta$ phase to $\alpha$ phase occurs. This means that the alloy substrate is not exposed to high temperatures sufficient for the phase transformation during the PEO treatment.

In contrast to the highly crystalline coatings formed in the alkaline electrolyte, a poorly crystalline coating is developed in the acid electrolyte. The XRD pattern of the specimen treated in the acid electrolyte (Fig. 2) reveals very weak diffraction lines of rutile and anatase in addition to a halo peak at about $25^{\circ}$. The halo peak suggests the presence of an amorphous phase. Weak intensity of light emission during PEO in the acid electrolyte may imply that the temperature is not raised to a sufficiently high level 
to form highly crystalline oxides. Since the light emission in the second step PEO in the acid electrolyte is extremely low, the phases observed after the second step PEO is almost similar to that in the alkaline electrolyte.

Fig. 3 shows the surface and cross-sectional SEM images of the coated specimens. All the surfaces reveal the presence of pores and holes in the size of 0.1 to $3 \mu \mathrm{m}$, which are typical of PEO coatings. The development of such pores and holes are associated with dielectric breakdown, accompanying micro-discharges during PEO. From cross-sectional SEM images, the porosity is apparently lower in the coating formed in the acid electrolyte, compared with those in the alkaline electrolyte and in the two-step PEO, probably due to the weak discharges in the acid electrolyte. In the alkaline electrolyte, a number of voids are visible in the coating immediately above the alloy/coating interface. Thus, the coating is likely to detach readily from the substrate. In contrast, the voids appear to be filled with oxide after the two-step PEO because of the formation of new oxide at the alloy/coating interface during the second step PEO in the acid electrolyte.

For further detailed characterization of the coatings, STEM observations have been carried out. Fig, 4 shows the scanning transmission electron micrographs of the Ti-15-3 specimen after PEO treatment in the alkaline electrolyte. Three different modes of images, i.e., secondary electron images (Figs. 4a,b), Z-contrast images (Figs. 4c,d) and transmission electron images (Figs. 4e,f), are taken to disclose more clearly the morphological and compositional information of the coatings. A region close to the alloy/coating interface is revealed in Figs. 4b, d, f, while a slightly upper part from the interface is shown in Figs. 4a,c,e. The presence of a number of pores and voids are obvious from the transmission electron image, particularly in the coating close to the 
alloy/coating interface, while the compositional non-uniformity is visible from the contrasts in the secondary electron mages and Z-contrast images. The selected area electron diffraction patterns, taken from the regions A and B reveal the presence of $\mathrm{Al}_{2} \mathrm{TiO}_{5}$ and $\gamma-\mathrm{Al}_{2} \mathrm{O}_{3}$ in agreement with the XRD patterns. In addition, the region $\mathrm{A}$ contains rutile, such that this region has a lighter appearance, due to atomic number contrast.

Fig. 5 shows the EDS images of the inner part of the coating formed in the alkaline electrolyte. Inhomogeneous distributions of elements are evident (Fig. 5a), in agreement with the contrast of the Z-contrast and secondary electron images. The concentration of aluminium is relatively high in the region of darker appearance, while the titanium and vanadium is rich in the region of light appearance in the secondary electron image. This result also supports that aluminium in the coating is mainly derived from the electrolyte. Phosphorus species are enriched in the coating region close to the alloy/coating interface, as in the previous reports [16, 20], although the mechanism of phosphate enrichment in the inner region is still unclear.

Scanning transmission electron micrographs of the two-step PEO coating (Fig. 6) shows only the circular pores of the sizes of $300 \mathrm{~nm}$ or less; larger voids found in the coating formed in the alkaline electrolyte are no longer visible. Apart from the presence of pores, this coating region is apparently compositionally uniform, except for the distributions of sulphur and phosphorus, as is confirmed by EDS elemental images shown in Fig. 7. Sulphur species, derived from the acid electrolyte, are enriched in the coating immediately above the substrate, while phosphorus species distributes more uniformly in the observed region. The selected area diffraction patterns of this region (Fig. 6) reveal that the oxide is amorphous, in contrast to the coating formed in the 
alkaline electrolyte. The aluminium content is rather low such that this inner coating region, more than $5 \mu \mathrm{m}$ in thickness, should be formed by the second step PEO in the acid electrolyte.

In another region of the two-step PEO coating (Fig. 8), two-layer structure is obvious (Fig. 8b), and in this region a high density of pores and voids are still remained in the coating close to the alloy/coating interface (Figs. 8d and f). The inner layer with lighter appearance (Figs. 8b and d) is amorphous (Fig. 8b), while the outer layer is highly crystalline and contains $\mathrm{Al}_{2} \mathrm{TiO}_{5}$ and $\gamma-\mathrm{Al}_{2} \mathrm{O}_{3}$ (Fig. 8a). Thus, the amorphous layer of $\sim 2.2 \mu \mathrm{m}$ thickness, located beneath the coating formed in the alkaline electrolyte, should be formed by the second step PEO in the acid electrolyte. The formation of the inner layer in the acid electrolyte is also confirmed from the relatively low aluminium content and higher concentrations of titanium and vanadium in the inner layer (Fig. 9). Enrichment of sulphur species immediately above the substrate is observed also in Fig. 9. From the comparison of Figs. 6 and 8, it is likely that the high density of pores and voids in the coating closed to the alloy/coating interface, developed during PEO in the alkaline electrolyte, is filled gradually with oxide formed during the second-step PEO in the acid electrolyte. Healing of the voids during the second step PEO should contribute to the improved adhesion of the coating as discussed later.

\subsection{Wear resistance and adhesion of PEO coatings}

The wear resistance of the PEO coatings formed in the acid and alkaline electrolytes and the two-step PEO coating was examined using a ball-on-disk tribometer under a load of $2 \mathrm{~N}$ for a sliding distance of $25 \mathrm{~m}$. The wear depths after the ball-on-disk tribometer test are summarized in Table 1 . The wear depth of the Ti-15-3 
without coating is $8 \mu \mathrm{m}$, while the specimens after PEO coating in the alkaline electrolyte and in the two-step process show undetectable wear depth. In contrast, a high wear depth of $10 \mu \mathrm{m}$ is revealed for the specimen PEO-coated in the acid electrolyte. Thus, highly crystalline oxide coatings, consisting mainly of $\mathrm{Al}_{2} \mathrm{TiO}_{5}$, improve markedly the wear resistance. In the two-step PEO coating, the highly crystalline oxide layer formed in the first step in the alkaline electrolyte remains in the outer part of the coating, with the new coating material developing mostly beneath the initially formed coating during the second step PEO. The poorly crystalline oxide coating formed in the acid electrolyte does not provide sufficient wear resistance, such that the coating is apparently completely lost under the present experimental condition, since the wear depth is deeper than the coating thickness. SEM images of the worn surfaces of the coated and non-coated specimens (Fig. 10) reveal the wider worn width for the specimen PEO-coated in the acid electrolyte, while the width is much narrower for the specimens PEO-coated in the alkaline electrolyte and coated by the two-step PEO. For the latter two specimens, materials worn from the counter SUJ2 steel appear to cover partly the coatings. The micro-hardness of the coating formed in the alkaline electrolyte was 5.3 GPa, which is much higher than that of alloy substrate (2.9 GPa) [20]. The improved wear resistance must be associated with the formation of a hard oxide coating in the alkaline electrolyte. The micro-hardness of the coating formed in the acid electrolyte was less than that of the alloy substrate, leading to the rapid wear loss of the coating.

Although the coating formed in the acid electrolyte has poor wear resistance, the coating adhesion to substrate is much higher than that in the alkaline electrolyte, as shown in Table 1 . The poor adhesion of the coating formed in the alkaline electrolyte 
must be associated with a high density of pores and voids in the coating close to the alloy/coating interface. Since such pores and voids are partly filled with oxide after the second step PEO treatment, the adhesion of the coating is highly improved by the two-step PEO. The formation of a low-hardness oxide layer formed in the acid electrolyte, which sandwiched between the hard outer coating and the alloy substrate, may also some positive effect in improving the adhesion by decreasing the internal stress.

It is known that electrolyte composition influences markedly the PEO process and hence the composition and structure of the coatings [1]. Present study demonstrates that the coatings with desired properties, such as good adhesion and wear resistance, can be tailored by combining the PEO treatments in different electrolytes. For instance, the coatings with high wear resistance as well as high corrosion resistance would be developed by forming a highly crystalline, hard oxide outer layer and a dense and less porous inner layer.

\section{Conclusions}

A highly crystalline, wear-resistant ceramic coating with $\mathrm{Al}_{2} \mathrm{TiO}_{5}$ as a major oxide phase is formed on a $\beta$-phase Ti-15V-3Al-3Cr-3Sn by plasma electrolytic oxidation in alkaline aluminate electrolyte. The coating contains a high density of pores and voids in the coating region close to the alloy/coating interface, such that the coating is poorly adherent to the substrate. Subsequent PEO treatment in acid electrolyte containing 0.1 mol dm ${ }^{-3} \mathrm{H}_{2} \mathrm{SO}_{4}$ and $0.1 \mathrm{~mol} \mathrm{dm}{ }^{-3} \mathrm{H}_{3} \mathrm{PO}_{4}$ form a new oxide of amorphous structure between the coating formed in the alkaline electrolyte and alloy substrate. The oxide 
fills partly the pores and voids gradually during the second step PEO, improving largely the adhesion of the coating without reducing the high wear resistance.

Acknowledgments

The present work was supported in part by a Grant-in-Aid for Scientific Research (A) No. 19206077 from the Japan Society for the Promotion of Science.

References

[1] A.L. Yerokhin, X. Nie, A. Leyland, A. Matthews, S.J. Dowey, Surf. Coat. Technol., 122 (1999) 73-93.

[2] F.C. Walsh, C.T.J. Low, R.J.K. Wood, K.T. Stevens, J. Archer, A.R. Poeton, A. Ryder, Trans. Inst. Met. Finish., 87 (2009) 122-135.

[3] M.D. Klapkiv, H.M. Nykyforchyn, V.M. Posuvailo, Mater. Sci., 30 (1994) 333-344.

[4] A. Maximov, A. Khlustova, Surf. Coat. Technol., 201 (2007) 8782-8788.

[5] E. Matykina, R. Arrabal, F. Monfort, P. Skeldon, G.E. Thompson, Appl. Surf. Sci., 255 (2008) 2830-2839.

[6] E. Matykina, R. Arrabal, P. Skeldon, G.E. Thompson, Electrochim. Acta, 54 (2009) 6767-6778.

[7] R. Arrabal, E. Matykina, F. Viejo, P. Skeldon, G.E. Thompson, Corros. Sci., 50 (2008) 1744-1752.

[8] C. Blawert, V. Heitmann, W. Dietzel, H.M. Nykyforchyn, M.D. Klapkiv, Surf. Coat. Technol., 201 (2007) 8709-8714.

[9] A. Bloyce, P.Y. Qi, H. Dong, T. Bell, Surf. Coat. Technol., 107 (1998) 125-132. 
[10] H.P. Duan, C.W. Yan, F.H. Wang, Electrochim. Acta, 52 (2007) 3785-3793.

[11] H.F. Guo, M.Z. An, Appl. Surf. Sci., 246 (2005) 229-238.

[12] D.Y. Hwang, Y.A. Kim, D.H. Shin, Mater. Trans., 50 (2009) 671-678.

[13] J. Liang, B.G. Guo, J. Tian, H.W. Liu, J.F. Zhou, W.M. Liu, T. Xu, Surf. Coat. Technol., 199 (2005) 121-126.

[14] J. Liang, P.B. Srinivasan, C. Blawert, M. Stormer, W. Dietzel, Electrochim. Acta, 54 (2009) 3842-3850.

[15] Y. Ma, X. Nie, D.O. Northwood, H. Hu, Thin Solid Films, 494 (2006) 296-301.

[16] S.P. Sah, Y. Aoki, H. Habazaki, Mater. Trans., 51 (2010) 94-102.

[17] P.B. Srinivasan, C. Blawert, W. Dietzel, Mater. Sci. Eng. A, 494 (2008) 401-406.

[18] P. Su, X.H. Wu, Y. Guo, Z. Jiang, J. Alloys Compd., 475 (2009) 773-777.

[19] J.E. Gray, B. Luan, J. Alloys Compd., 336 (2002) 88-113.

[20] H. Habazaki, T. Onodera, K. Fushimi, H. Konno, K. Toyotake, Surf. Coat. Technol., 201 (2007) 8730-8737.

[21] Y.M. Wang, B.L. Jiang, L.X. Guo, T.C. Lei, Mater. Sci. Technol., 20 (2004) 1590-1594.

[22] L. Ceschini, E. Lanoni, C. Martini, D. Prandstraller, G. Sambogna, Wear, 264 (2008) 86-95.

[23] L.R. Krishna, K.R.C. Somaraju, G. Sundararajan, Surf. Coat. Technol., 163 (2003) 484-490.

[24] X.T. Sun, Z.H. Jiang, S.G. Xin, Z.P. Yao, Thin Solid Films, 471 (2005) 194-199.

[25] Y.M. Wang, B.L. Jiang, L.X. Guo, T.Q. Lei, Appl. Surf. Sci., 252 (2006) 2989-2998. 
[26] Y.M. Wang, T.Q. Lei, L.X. Guo, B.L. Jiang, Appl. Surf. Sci., 252 (2006) 8113-8120.

[27] T.B. Wei, F.Y. Yan, J. Tian, J. Alloys Compd., 389 (2005) 169-176.

[28] H.H. Wu, H.B. Wang, B.Y. Long, B.H. Long, Z.S. Jin, N.D. Wang, F.G. Yu, D.M. Bi, Appl. Surf. Sci., 252 (2005) 1545-1552.

[29] W.B. Xue, C. Wang, Z.W. Deng, R.Y. Chen, Y.L. Li, T.H. Zhang, J. Phys.-Condes. Matter, 14 (2002) 10947-10952.

[30] W.B. Xue, J.C. Du, X.L. Wu, Y.C. Lai, ISIJ Int., 46 (2006) 287-291.

[31] P. Huang, K.W. Xu, Y. Han, Mater. Lett., 59 (2005) 185-189.

[32] L.H. Li, H.W. Kim, S.H. Lee, Y.M. Kong, H.E. Kim, J. Biomed. Mater. Res. Part A, 73A (2005) 48-54.

[33] D.Q. Wei, Y. Zhou, D.C. Jia, Y.M. Wang, Acta Biomaterialia, 3 (2007) 817-827.

[34] M. Nakajima, Y. Miura, K. Fushimi, H. Habazaki, Corros. Sci., 51 (2009) 1534-1539.

[35] E. Matykina, F. Monfort, A. Berkani, P. Skeldon, G.E. Thompson, P. Chapon, Philos. Mag., 86 (2006) 49-66.

[36] F. Monfort, A. Berkani, E. Matykina, P. Skeldon, G.E. Thompson, H. Habazaki, K. Shimizu, Corros. Sci., 49 (2007) 672-693.

[37] W.B. Xue, C. Wang, R.Y. Chen, Z.W. Deng, Mater. Lett., 52 (2002) 435-441.

[38] Z.P. Yao, Y.J. Xu, Z.H. Jiang, F.P. Wang, J. Alloys Compd., 488 (2009) 273-278.

[39] J.M. Wheeler, C.A. Collier, J.M. Paillard, J.A. Curran, Surf. Coat. Technol., 204 (2010) 3399-3409. 
Figure captions

Fig. 1 (a) Changes in peak voltage and photo intensity during PEO treatment of Ti-15-3 specimens in alkaline aluminate and mixed sulphuric and phosphoric acid electrolytes as well as during the second step PEO in the acid electrolyte. (b) Change in the light intensity during PEO treatments for initial $100 \mathrm{~s}$.

Fig. 2 X-ray diffraction patterns of the Ti-15-3 specimens after PEO coatings in (a) mixed sulphuric and phosphoric acid electrolyte, (b) alkaline aluminate electrolyte as well as (c) after the two-step PEO in the alkaline and following acid electrolytes.

Fig. 3 Scanning electron micrographs of (a, c, e) surfaces and (b, d, f) cross-sections of the Ti-15-3 specimens after PEO coatings in (a, b) mixed sulphuric and phosphoric acid electrolyte, (c, d) alkaline aluminate electrolyte as well as (e, f) after the two-step PEO in the alkaline and following acid electrolytes.

Fig. 4 Scanning transmission electron micrographs of the Ti-15-3 specimen after PEO coating in alkaline aluminate electrolyte: (a,b) secondary electron images, (c, d) Z-contrast images and (e, f) transmission electron images.

Fig. 5 Scanning transmission electron micrograph and EDS images (Fig. 4b region) of the Ti-15-3 specimen after PEO coating in alkaline aluminate electrolyte: (a) secondary electron image, (b) oxygen image, (c) titanium image, (d) aluminium image, (e) vanadium image and (f) phosphorus image. 
Fig. 6 Scanning transmission electron micrographs of the Ti-15-3 specimen after two-step PEO coating in alkaline aluminate and following mixed sulphuric and phosphoric acid electrolytes: (a,b) secondary electron images, (c, d) Z-contrast images and (e, f) transmission electron images.

Fig. 7 Scanning transmission electron micrograph and EDS images (Fig. 6b region) of the Ti-15-3 specimen after two-step PEO coating in alkaline aluminate and following mixed sulphuric and phosphoric acid electrolytes: (a) secondary electron image, (b) oxygen image, (c) titanium image, (d) aluminium image, (e) vanadium image, phosphorus image and (g) sulphur image.

Fig. 8 Scanning transmission electron micrographs of the Ti-15-3 specimen after two-step PEO coating in alkaline aluminate and following mixed sulphuric and phosphoric acid electrolytes: (a, b) secondary electron images, (c, d) Z-contrast images and $(\mathrm{e}, \mathrm{f})$ transmission electron images. The specimen is the same as that in Fig. 6, but a different region.

Fig. 9 Scanning transmission electron micrograph and EDS images (Fig. 8b region) of the Ti-15-3 specimen after two-step PEO coating in alkaline aluminate and following mixed sulphuric and phosphoric acid electrolytes: (a) secondary electron image, (b) oxygen image, (c) titanium image, (d) aluminium image, (e) vanadium image, phosphorus image and (g) sulphur image. 
Fig. 10 Scanning electron micrographs of the Ti-15-3 specimens of the worn regions after the pin-on-disk wear test under unlubricated condition for a sliding distance of 25 m under a load of $2 \mathrm{~N}$ of SUJ2 steel ball: (a) without PEO coating, (b) after PEO in mixed sulphuric and phosphoric acid electrolyte, (c) after PEO in alkaline aluminate electrolyte and (d) after the two-step PEO. 
Table 1 Thicknesses, wear depths and adhesion of the PEO coatings.

\begin{tabular}{ccccc}
\hline & \multicolumn{4}{c}{ Electrolyte } \\
\cline { 2 - 5 } & No coating & Alkaline & Acid & Alkaline + acid \\
\hline $\begin{array}{c}\text { Coating thickness } \\
(\mu \mathrm{m})\end{array}$ & - & $14.2 \pm 1.4$ & $8.6 \pm 1.7$ & $14.5 \pm 1.9$ \\
\hline $\begin{array}{c}\text { Wear depth } \\
(\mu \mathrm{m})\end{array}$ & 8.0 & $<0.1$ & 10 & $<0.1$ \\
\hline $\begin{array}{c}\text { Adhesion force } \\
(\mathrm{MPa})\end{array}$ & - & $1.4 \pm 0.4$ & $6.4 \pm 1.8$ & $4.1 \pm 0.5$ \\
\hline
\end{tabular}




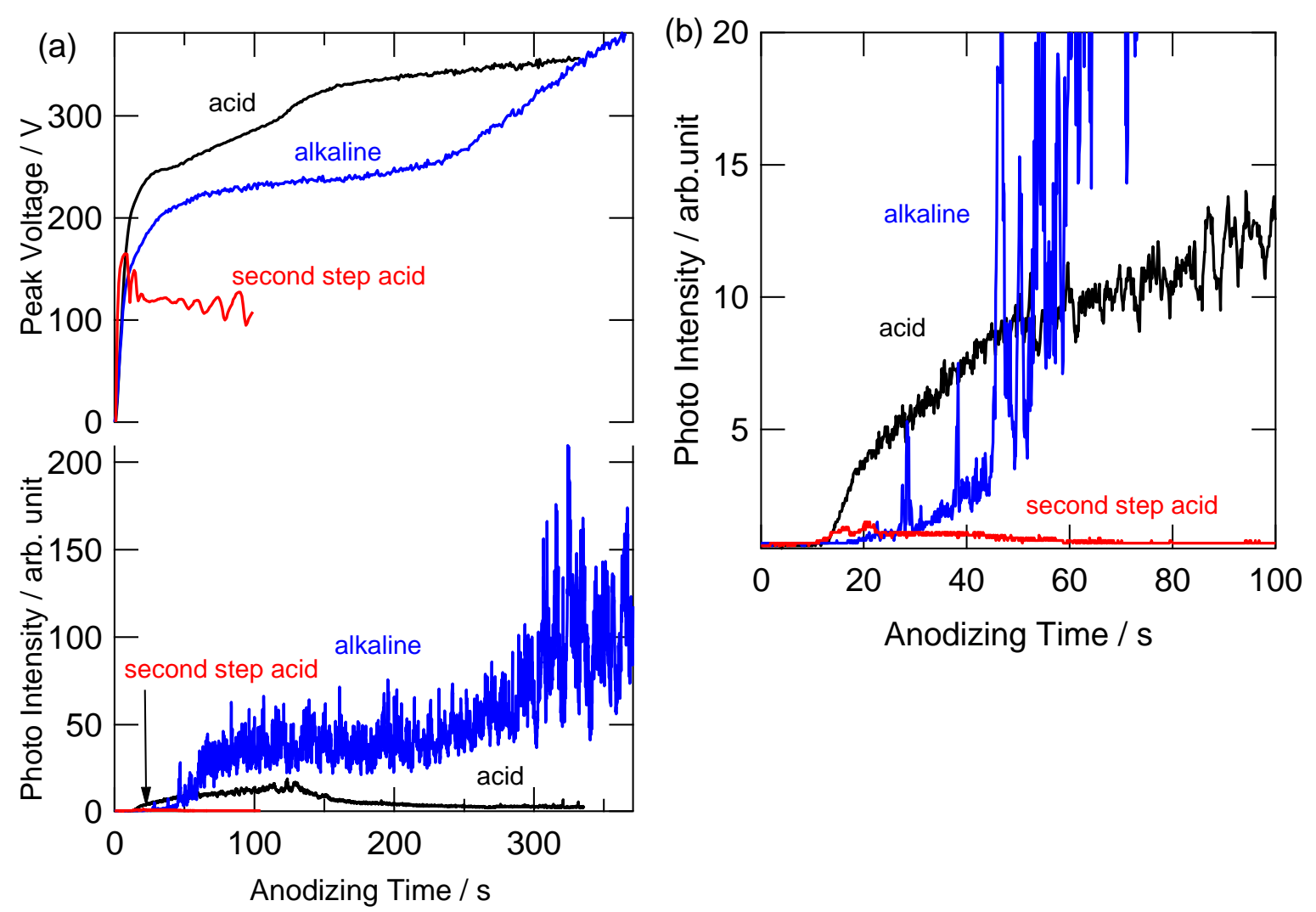

Fig. 1 (a) Changes in peak voltage and photo intensity during PEO treatment of Ti-15-3 specimens in alkaline aluminate and mixed sulphuric and phosphoric acid electrolytes as well as during the second step PEO in the acid electrolyte. (b) Change in the photo intensity during PEO treatments for initial $100 \mathrm{~s}$. 


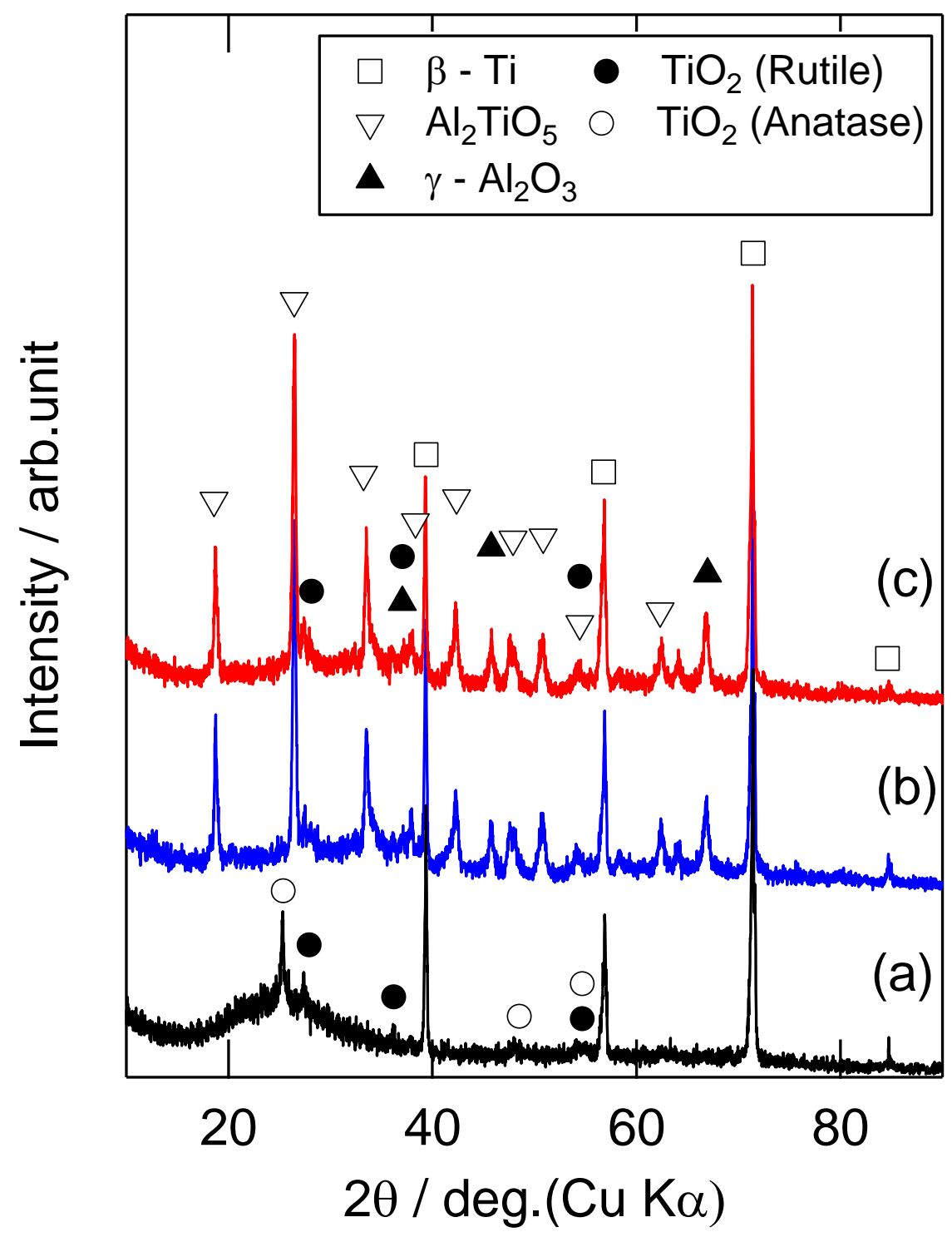

Fig. $2 \mathrm{X}$-ray diffraction patterns of the Ti-15-3 specimens after PEO coatings in (a) mixed sulphuric and phosphoric acid electrolyte, (b) alkaline aluminate electrolyte as well as (c) after two-step PEO in the alkaline and following acid electrolytes. 

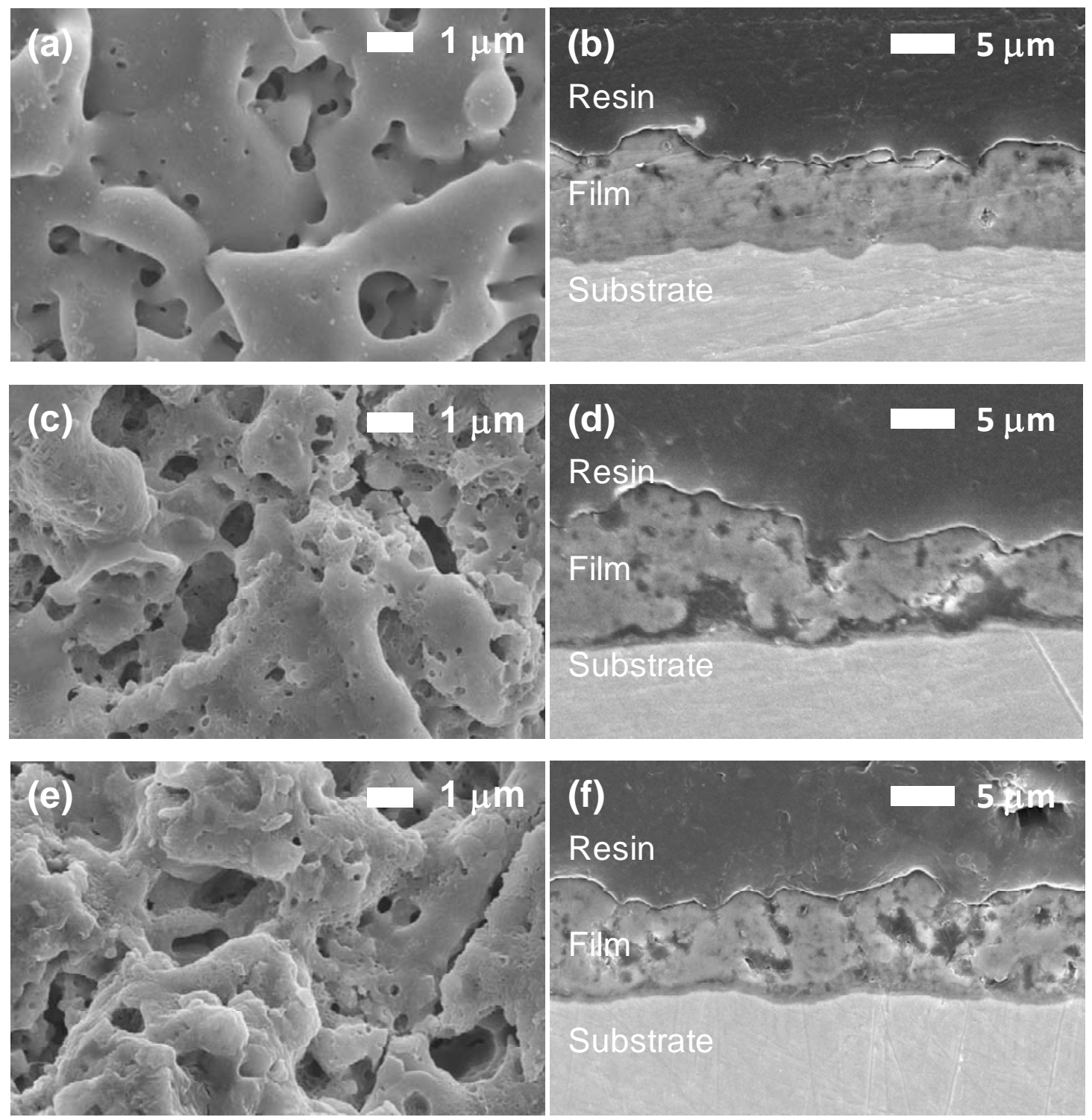

Fig. 3 Scanning electron micrographs of ( $a, c, e)$ surfaces and (b, d, f) cross-sections of the Ti-15-3 specimens after PEO coatings in (a,b) mixed sulphuric and phosphoric acid electrolyte, (c, d) alkaline aluminate electrolyte as well as (e, f) after two-step PEO in the alkaline and following acid electrolytes. 

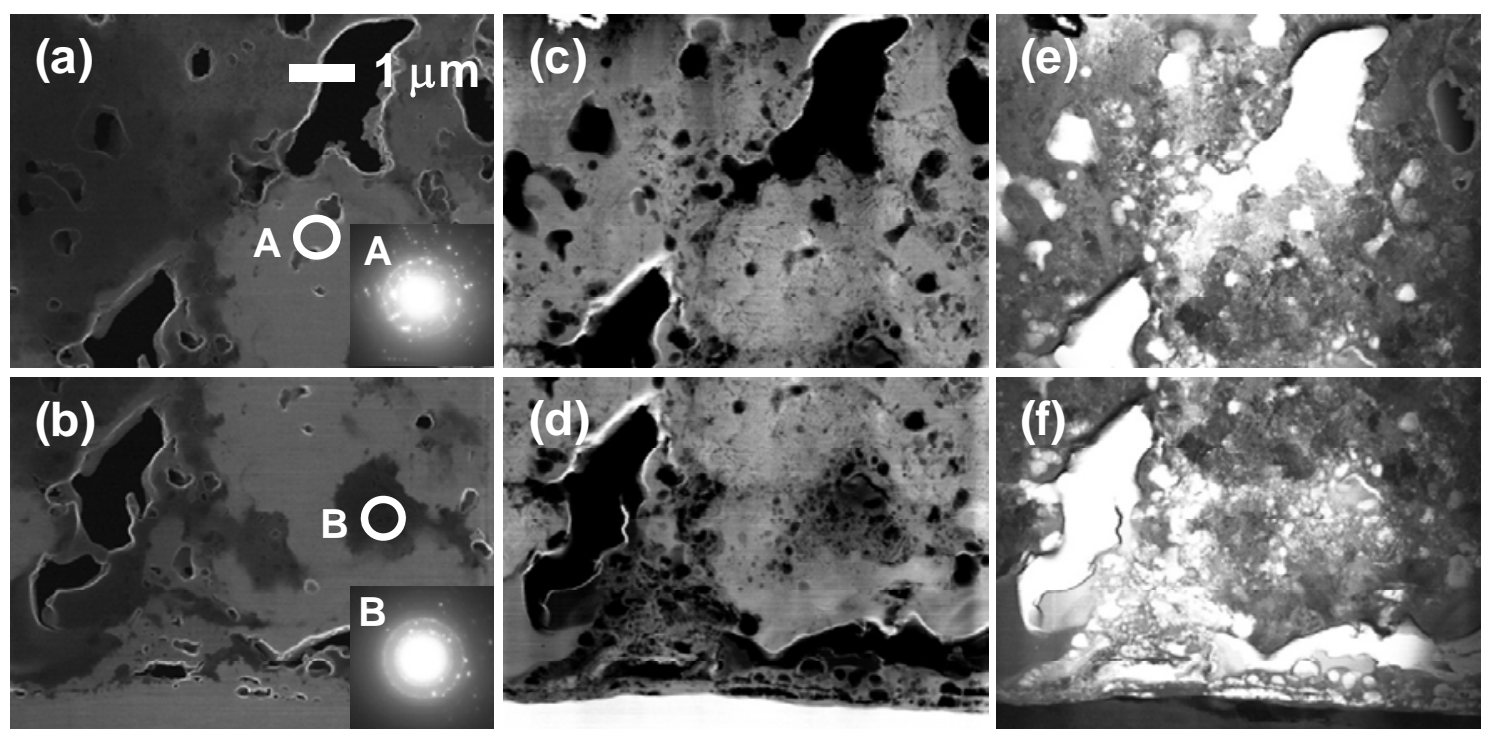

Fig. 4 Scanning transmission electron micrographs of the Ti-15-3 specimen after PEO coating in alkaline aluminate electrolyte: $(a, b)$ secondary electron images, (c, d) Z-contrast images and (e, f) transmission electron images. 

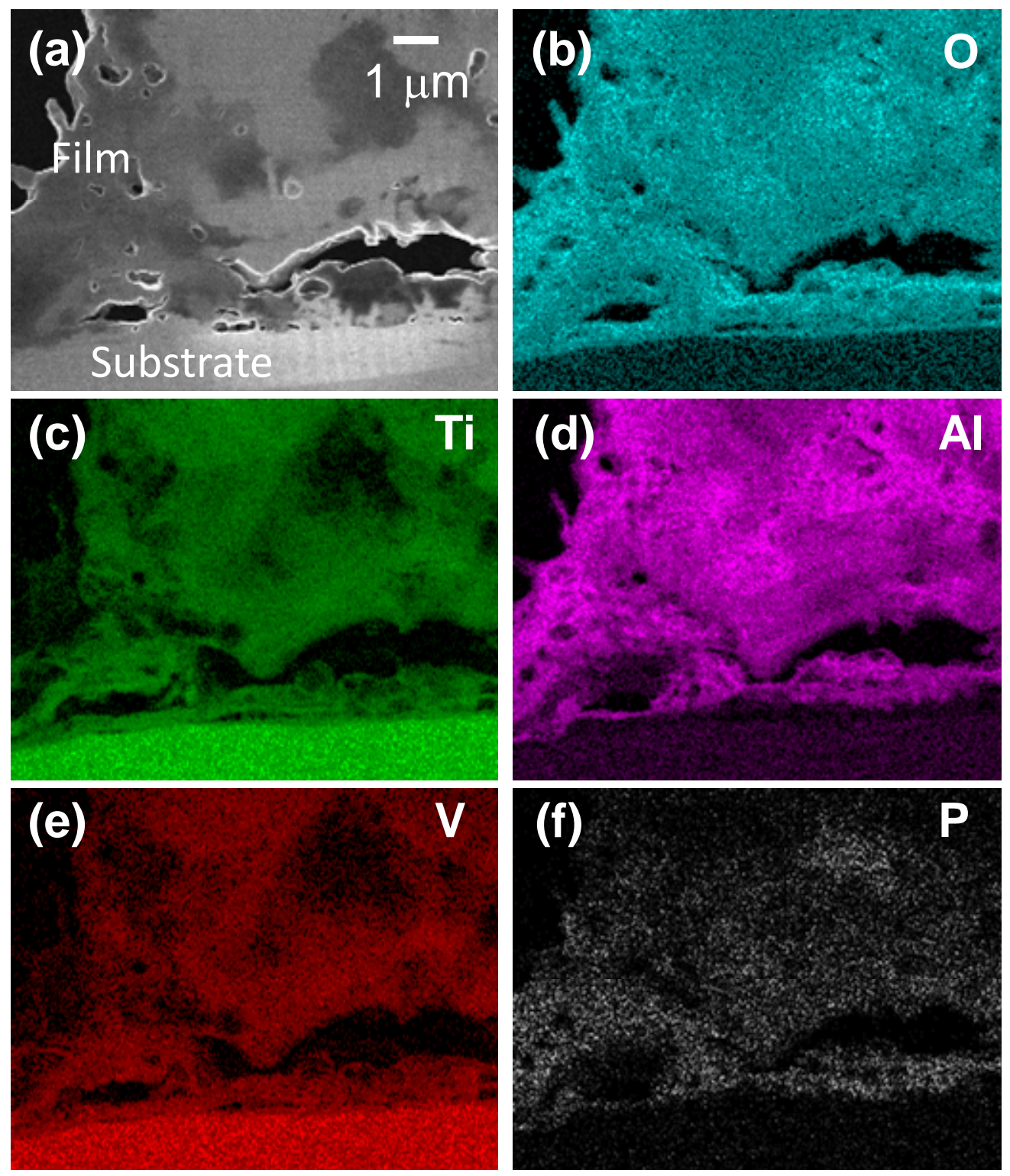

Fig. 5 Scanning transmission electron micrograph and EDS images (Fig. 4b region) of the Ti-15-3 specimen after PEO coating in alkaline aluminate electrolyte: (a) secondary electron image, (b) oxygen image, (c) titanium image, (d) aluminium image, (e) vanadium image and (f) phosphorus image. 

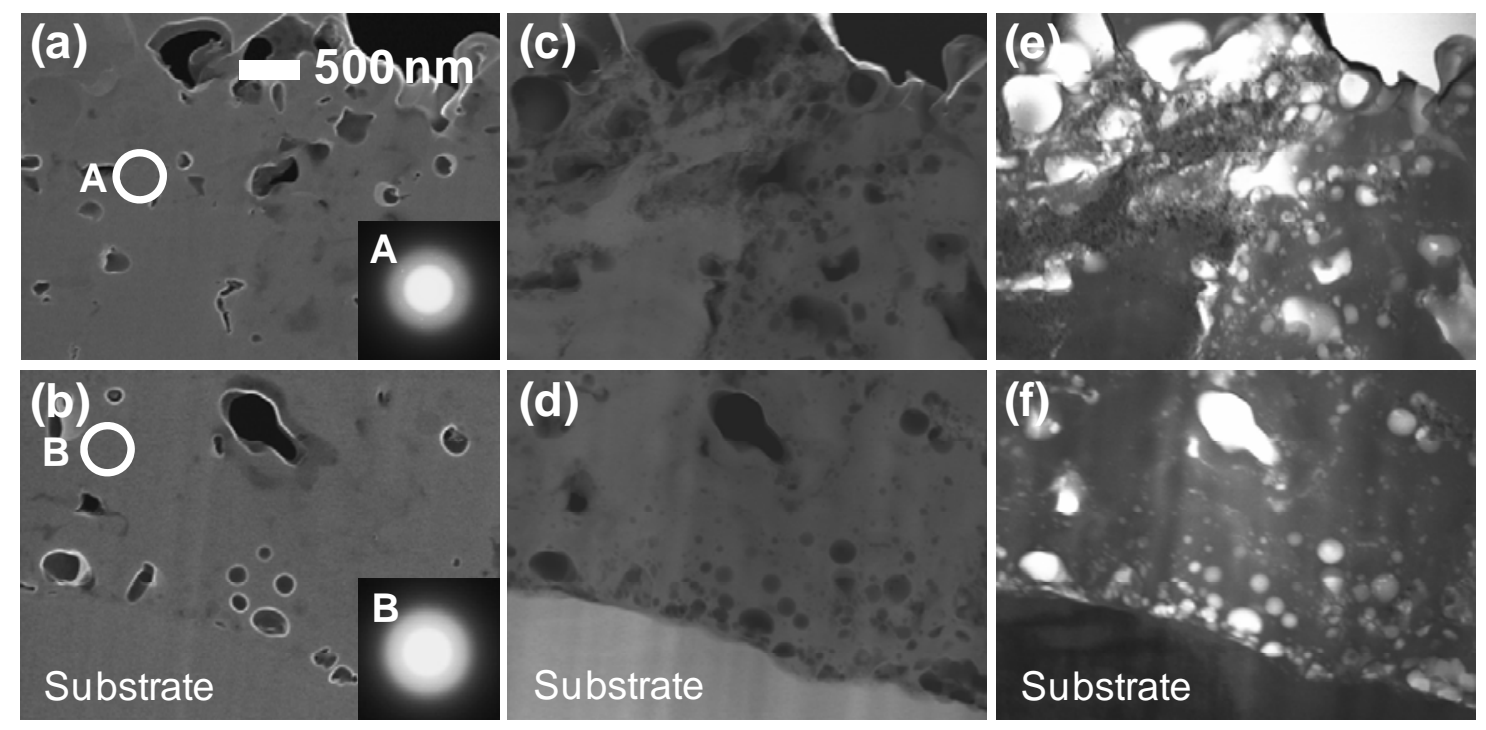

Fig. 6 Scanning transmission electron micrographs of the Ti-15-3 specimen after two-step PEO coating in alkaline aluminate and following mixed sulphuric and phosphoric acid electrolytes: $(a, b)$ secondary electron images, (c, d) Z-contrast images and (e, f) transmission electron images. 

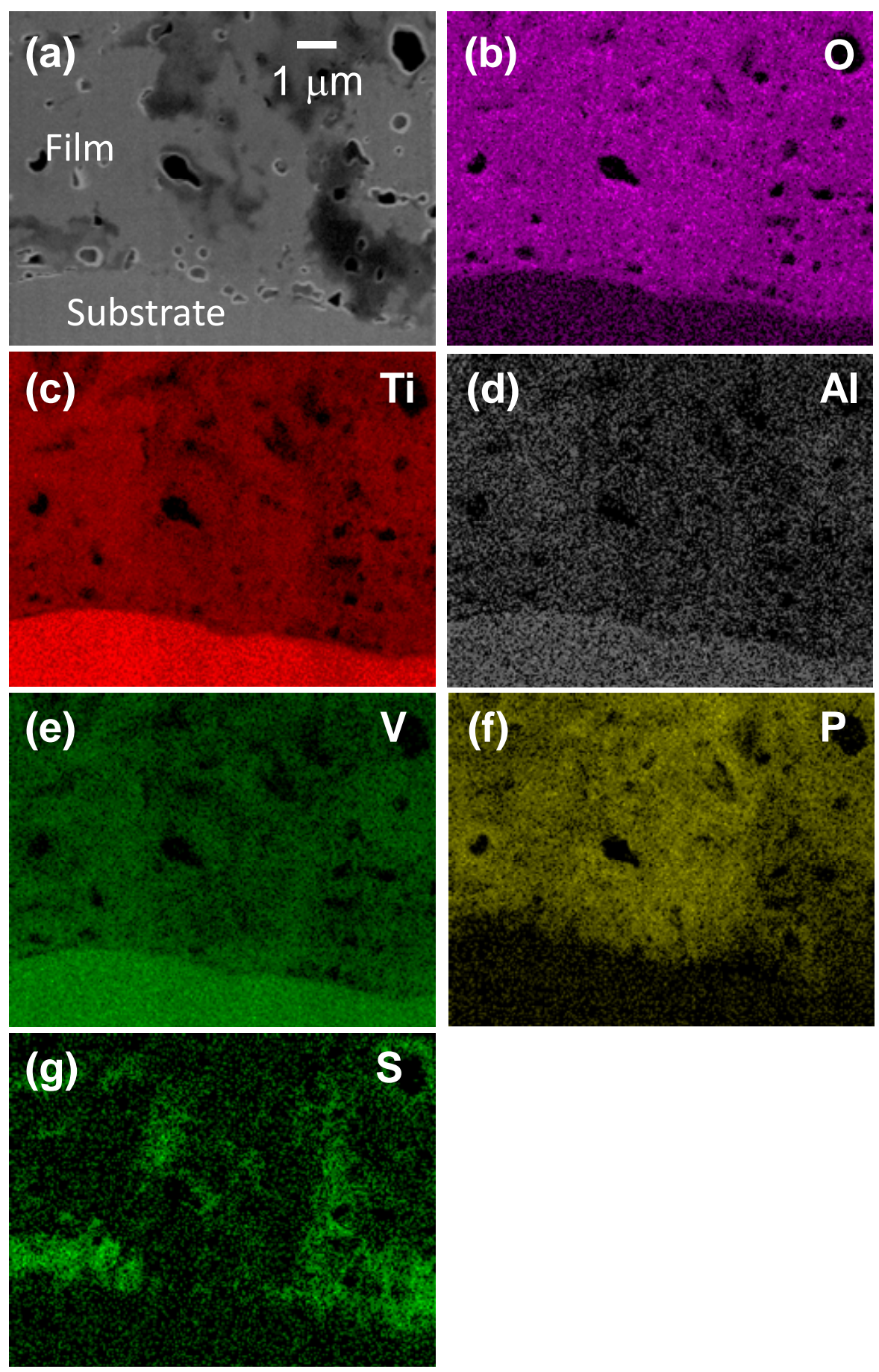

Fig. 7 Scanning transmission electron micrograph and EDS images (Fig. 6b region) of the Ti-15-3 specimen after two-step PEO coating in alkaline aluminate and following mixed sulphuric and phosphoric acid electrolytes: (a) secondary electron image, (b) oxygen image, (c) titanium image, (d) aluminium image, (e) vanadium image (f) phosphorus image and (g) sulphur image. 

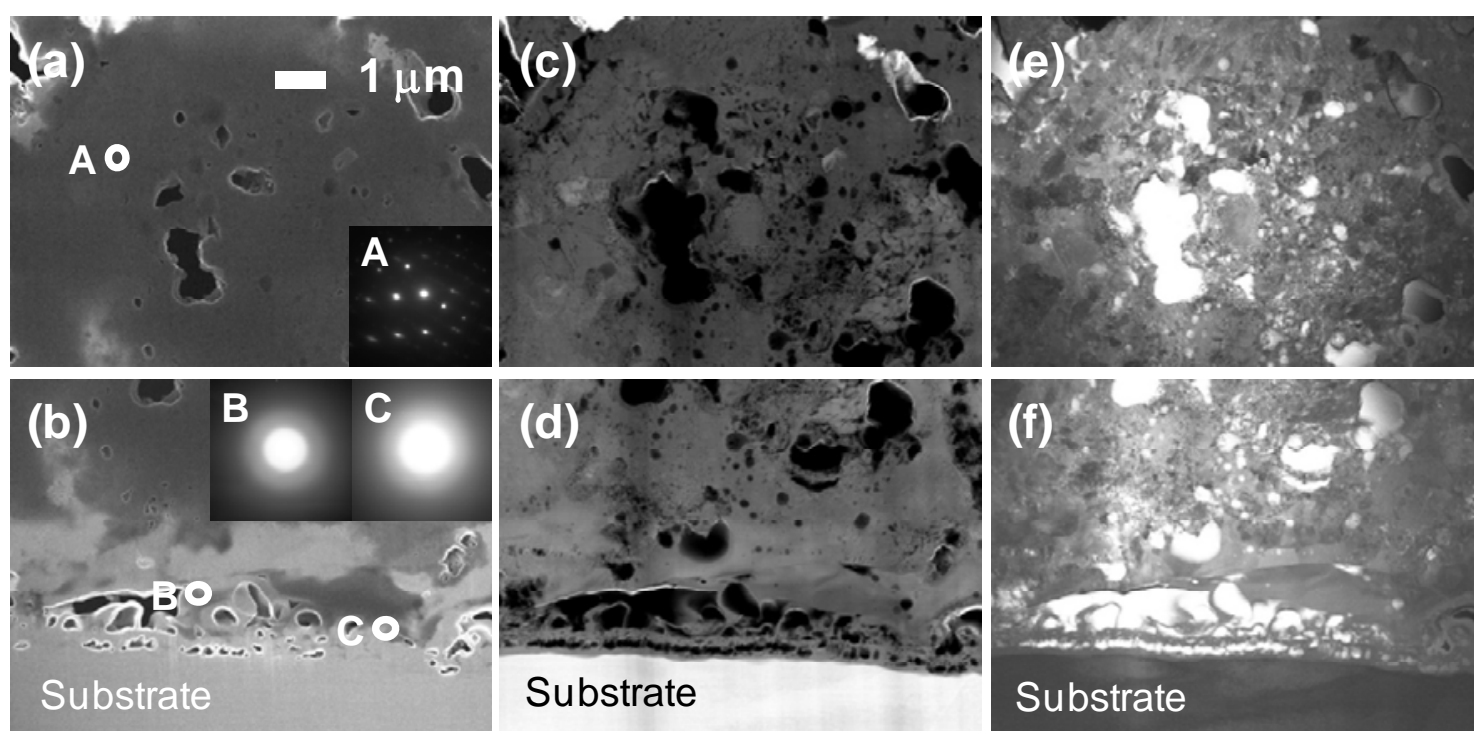

Fig. 8 Scanning transmission electron micrographs of the Ti-15-3 specimen after two-step PEO coating in alkaline aluminate and following mixed sulphuric and phosphoric acid electrolytes: $(a, b)$ secondary electron images, (c, d) Z-contrast images and (e, f) transmission electron images. The specimen is the same as that in Fig. 6, but a different region. 

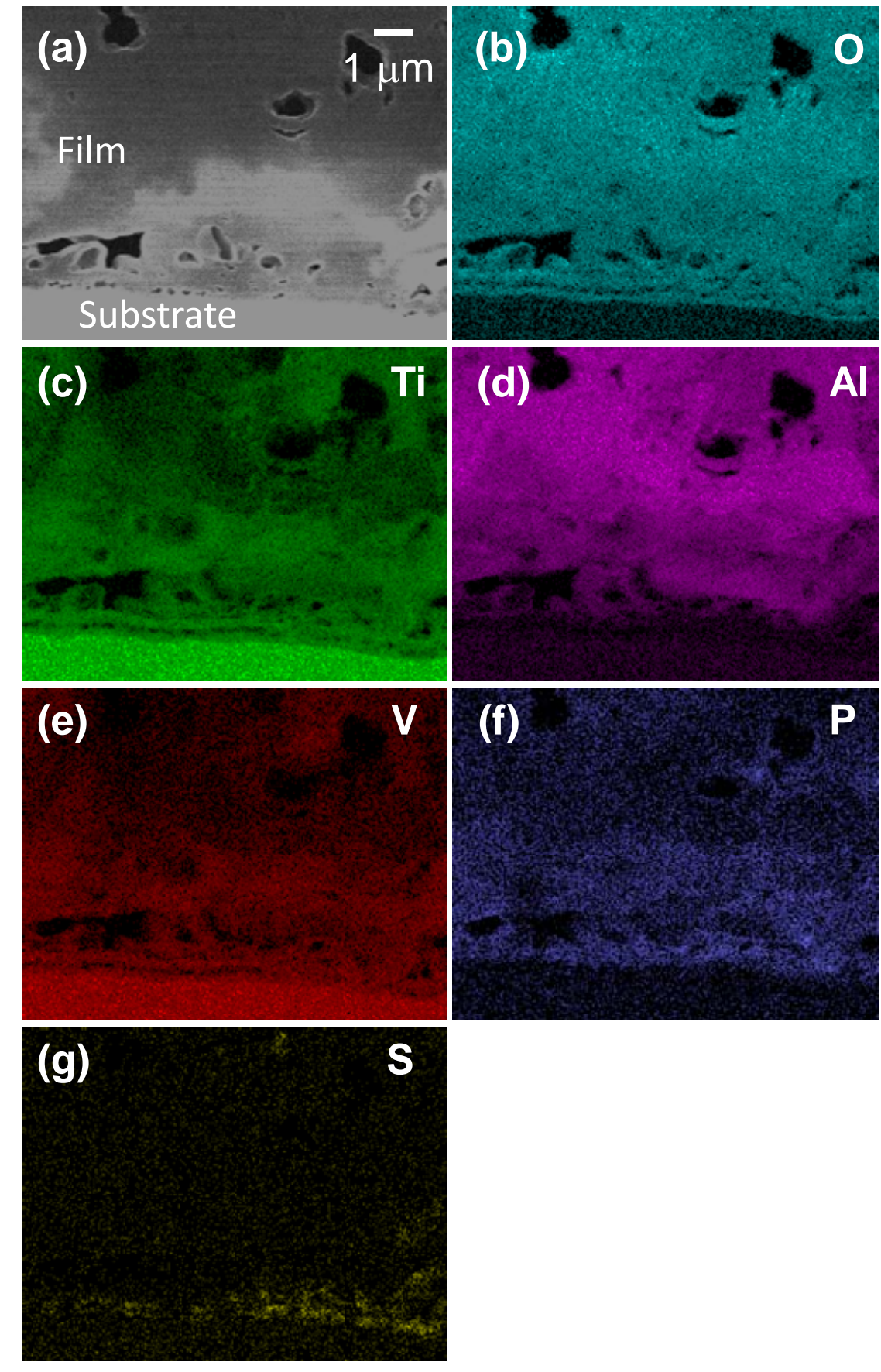

Fig. 9 Scanning transmission electron micrograph and EDS images (Fig. 8b region) of the Ti-15-3 specimen after two-step PEO coating in alkaline aluminate and following mixed sulphuric and phosphoric acid electrolytes: (a) secondary electron image, (b) oxygen image, (c) titanium image, (d) aluminium image, (e) vanadium image (f) phosphorus image and (g) sulphur image. 

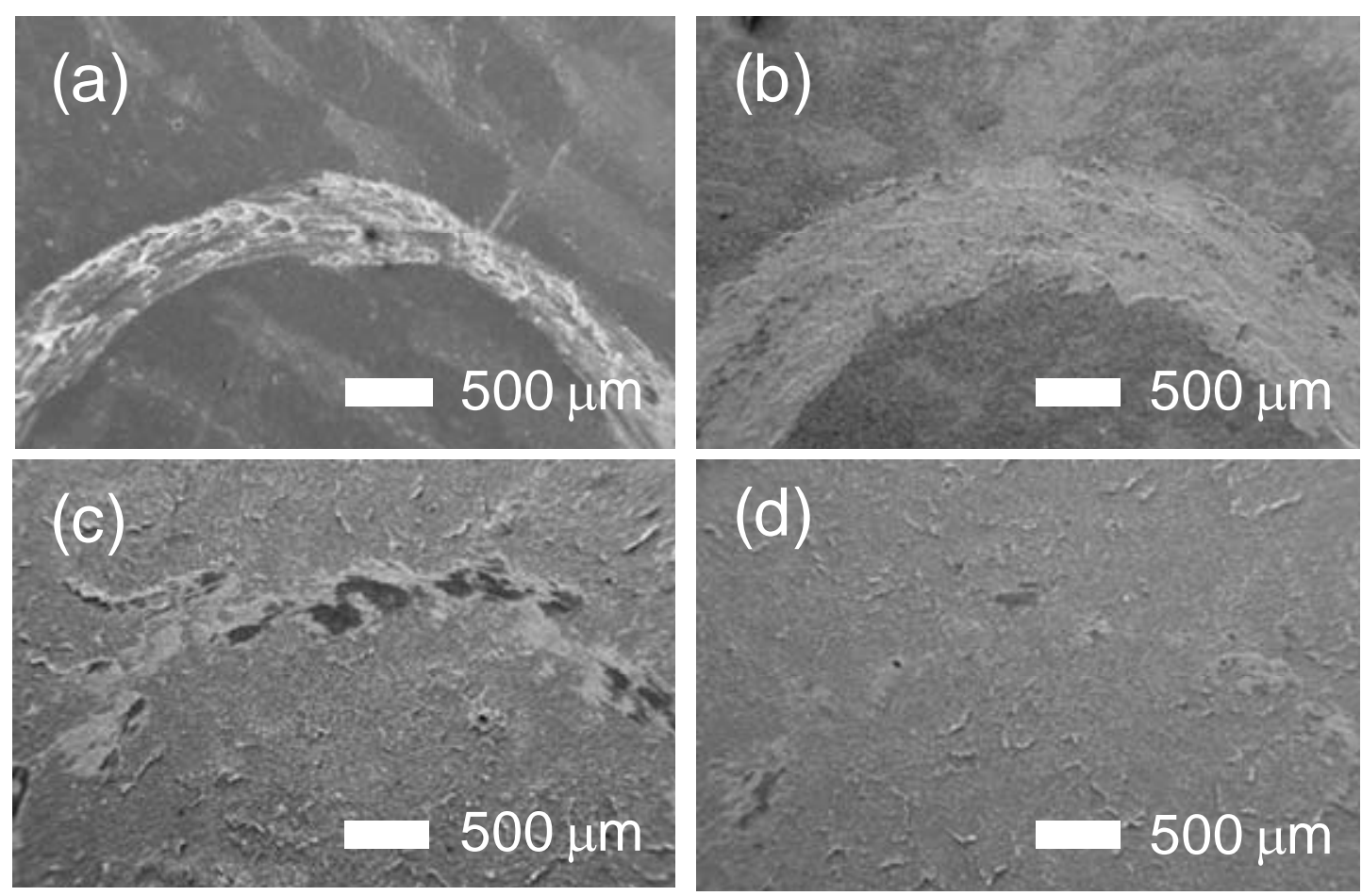

Fig. 10 Scanning electron micrographs of the Ti-15-3 specimens of the worn regions after the pin-on-disk wear test under unlubricated condition for a sliding distance of $25 \mathrm{~m}$ under a load of $2 \mathrm{~N}$ of SUJ2 steel ball: (a) without PEO coating, (b) after PEO in mixed sulphuric and phosphoric acid electrolyte, (c) after PEO in alkaline aluminate electrolyte and (d) after two-step PEO. 